\title{
"Metabolic and cardiovascular response to exercise in patients with type 1 diabetes"
}

Article in Journal of endocrinological investigation · April 2017

DOI: $10.1007 / \mathrm{s} 40618-017-0670-6$

CITATIONS

0

10 authors, including:

\section{Paolo Marinelli}

Sapienza University of Rome 18 PUBLICATIONS 57 CITATIONS

SEE PROFILE

\section{Alberto Paris}

Sapienza University of Rome 11 PUBLICATIONS 132 CITATIONS SEE PROFILE
READS

71

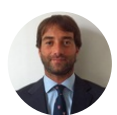

Matteo Bonini

Imperial College London

83 PUBLICATIONS 843 CITATIONS

SEE PROFILE

Susanna Morano

Sapienza University of Rome

113 PUBLICATIONS 1,635 CITATIONS

SEE PROFILE

Some of the authors of this publication are also working on these related projects: 


\title{
"Metabolic and cardiovascular response to exercise in patients with type 1 diabetes"
}

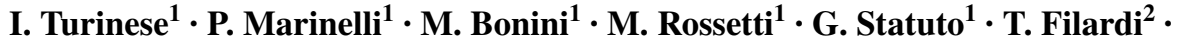

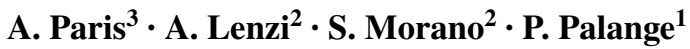

Received: 25 October 2016 / Accepted: 30 March 2017

(C) Italian Society of Endocrinology (SIE) 2017

\begin{abstract}
Purpose Physical activity is an effective therapeutic tool for cardiovascular risk prevention. However, exercise aerobic capacity of patients with type 1 diabetes (T1DM) has not been thoroughly investigated. Aim of the present study is to evaluate exercise aerobic capacity in patients with T1DM compared to a normal control population.

Methods This observational study included 17 T1DM patients and 17 matched healthy volunteers. Cardiopulmonary exercise test (CPET) was conducted on an electronically-braked cycle ergometer. Blood samples were collected for evaluation of glycemia and lactate levels.

Results Mean oxygen uptake at peak exercise $\left(\mathrm{V}^{\prime} \mathrm{O}_{2, \text { peak }}\right)$ was significantly lower in T1DM subjects $\left(\mathrm{V}^{\prime} \mathrm{O}_{2 \text {,peak }} \mathrm{T} 1 \mathrm{DM}\right.$ $2200 \pm 132 \mathrm{ml} / \mathrm{min}$ vs $\mathrm{V}^{\prime} \mathrm{O}_{2 \text {,peak }}$ Healthy subjects of 2659 $\pm 120 \mathrm{ml} / \mathrm{min} p=0.035$ ). Cardiovascular response analysis did not show statistically significant differences. Respiratory exchange ratio (RER) was significantly higher in healthy subjects at peak exercise and at the first minute of recovery $(p=0.022, p=0.024)$. Peak exercise lactate levels were significantly higher in healthy subjects. There was no statistical correlation between CPET results and diabetesrelated parameters.
\end{abstract}

I. Turinese

irene.turinese@uniroma1.it

1 Department of Public Health and Infectious Diseases, Sapienza University of Rome, Viale dell' Università 37, 00185 Rome, Italy

2 Department of Experimental Medicine, "Sapienza" University of Rome, Viale del Policlinico 151, 00185 Rome, Italy

3 Department of Clinical Medicine, "Sapienza" University of Rome, Viale dell' Università 37, 00185 Rome, Italy
Conclusions Patients affected by T1DM have a worse exercise tolerance than normal subjects. The two groups differed by RER which can be greatly influenced by the substrate type utilized to produce energy. Because of the impaired carbohydrate utilization, T1DM subjects may use a larger amount of lipid substrates, such hypothesis could be strengthened by the lower lactate levels found in T1DM group at peak exercise. The lack of correlation between exercise tolerance and disease-related variables suggests that the alterations found could be independent from the glycemic levels.

Keywords Diabetes mellitus - Exercise physiology · Physical activity $\cdot$ Cardiopulmonary exercise test

\section{Introduction}

Type-1 diabetes mellitus (T1DM) is a chronic disease characterized by chronic hyperglycemia and induced by immuno-mediated or idiopathic beta-cell destruction, which leads to lack of insulin production [1].

Treatment goals are prevention of microvascular and macrovascular complications, which are linked to chronic hyperglycemia and to the complex metabolic alterations associated with diabetes [2].

Insulin administration, generally with a basal-bolus protocol, represents the baseline treatment of T1DM. Anyhow, an optimal disease treatment should include a comprehensive intervention on cardiovascular risk factors (hypertension, dyslipidemia, obesity, and smoking), integrating pharmacological treatment and lifestyle changes.

Physical activity is an effective therapeutic tool for preventing cardiovascular risk in the general population, as well as in subjects with type-2 diabetes [3, 4]. Despite this, 
only few studies addressing the role of physical activity as a therapeutic strategy for T1DM have been performed up to 2011 [5].

Bohn et al. have recently demonstrated an association between physical activity and glycosylated hemoglobin (HbA1c), body mass index (BMI), dyslipidemia, hypertension, as well as between physical activity and retinopathy or microalbuminuria [6]. However, there is no agreement on the exercise aerobic capacity of patients with T1DM. Some studies did not find any difference in comparison to healthy subjects [7-9], while other authors found a reduced exercise aerobic capacity in T1DM subjects [10-13]. In these last studies, patients with T1DM showed reduced oxygen uptake at exercise peak $\left(\mathrm{V}^{\prime} \mathrm{O}_{2 \max }\right)$. Data from the Study of Health in Pomerania (SHIP) [14] confirmed a reduced exercise tolerance in adults with type 1 diabetes (mean age 50 years), showing a reduced $\mathrm{V}^{\prime} \mathrm{O}_{2 \max }$ and oxygen uptake at anaerobic threshold when compared to a matched population without type 1 diabetes. The authors speculate about a possible correlation with clinical status (metabolic, cardiac, respiratory, and peripheral vascular disease) and exercise performance, but the results could not be thoroughly explained. Moreover, the metabolic response to physical activity in T1DM is still not clearly defined, since most of the studies have been performed in strictly controlled conditions, such as clamp techniques [15, 16], or after insulin withdrawal [17] which cannot be applied to real-life models.

Aim of the current study is to evaluate exercise aerobic capacity in patients with T1DM in basal-bolus insulin therapy, compared to a healthy control population.

The relationship between exercise tolerance and pre-test glycaemia, and glycosylated hemoglobin and diabetes duration was also assessed.

\section{Materials and methods}

This observational preliminary study included 17 consecutive T1DM patients presenting between November 2014 and May 2015 to the Diabetic Center of the University Hospital Policlinico Umberto I, Rome; type 1 diabetes was diagnosed according to the American Diabetes Association (ADA) guidelines [1] in basal-bolus treatment, aged between 18 and 45 years, with a diabetes history of less than 15 years (to reduce the chance of comorbidities), HbAlc $<75 \mathrm{mmol} / \mathrm{L}$. As control group, 17 healthy volunteers matched for age, sex, BMI, and physical activity level were enrolled. Exclusion criteria were: patients unable or with contraindications to perform an exercise test; $\mathrm{HbA} 1 \mathrm{c} \geq 75 \mathrm{mmol} / \mathrm{L}$; diabetic ketoacidosis; macrovascular complications; proliferative diabetic retinopathy; respiratory diseases (COPD, asthma, and interstitial lung diseases); anemia; hypothyroidism or hyperthyroidism; pregnancy or lactation; menopause; clinical evidence or history of cancer; and medication (other than insulin). The presence of exclusion criteria was evaluated using medical records and the latest blood tests available.

Written informed consent was obtained from each subject. The study was approved by the Internal Review Board (IRB) and the local Ethics Committee and was performed according to the principles of the Declaration of Helsinki (1975)

Clinical assessment, blood pressure, heart rate, oxygen saturation, and anthropometric data (weight, height, and BMI) were obtained from each subject. All subjects compiled the International Physical Activity Questionnaire (IPAQ) to assess physical activity level [18].

A venous catheter was positioned to collect blood samples at rest and at peak exercise, for evaluation of blood glucose and lactate levels; collected samples were analyzed using a blood gas analyzer (GEM Premier 4000-Instrumentation Laboratory Worldwide Headquarters, Bedford, MA).

Before exercise testing, all subject performed a pulmonary function test with a Quark ${ }^{\circledR}$ PFT (COSMED, Pavona, Italy).

Cardiopulmonary exercise test (CPET) was conducted on an electronically-braked cycle ergometer (COSMED, Pavona Italy) using the Quark b 2 system (COSMED, Pavona, Italy) according to guidelines [19]. CPET consisted of a steady-state resting period, then 1 min of warmup without load, followed by a stepwise protocol in which the work rate was increased in 1-min intervals by increments of $15 \mathrm{~W}$. The test was continued until the point of symptom limitation (peak exercise). Subjects were asked to score their sense of breathlessness and muscle fatigue throughout the exercise and at peak exercise using Borg scale [20]. Oxygen saturation $\left(\mathrm{SpO}_{2}\right)$ by pulse oximetry, electrocardiographic monitoring of heart rate (HR), blood pressure (BP), oxygen uptake $\left(\mathrm{V}^{\prime} \mathrm{O}_{2}\right)$, carbon dioxide production $\left(\mathrm{V}^{\prime} \mathrm{CO}_{2}\right)$, and minute ventilation $\left(\mathrm{V}^{\prime} \mathrm{E}\right)$ were collected. Ventilation was compared with the maximal ventilatory capacity (MVC), which was estimated by multiplying the measured FEV 1 (forced expiratory volume in $1 \mathrm{~s}$ ) by 40 [21]. The Lactic Threshold (LT) was detected individually using the V-slope method [22]. The ventilatory compensation point (VCP) estimation was based on $\mathrm{V}^{\prime} \mathrm{E} / \mathrm{V}^{\prime} \mathrm{CO}_{2}$ relationship, where $\mathrm{V}^{\prime} \mathrm{E}$ started to change out of proportion of $\mathrm{V}^{\prime} \mathrm{CO}_{2}$ and $\mathrm{P}_{\mathrm{ET}} \mathrm{CO}_{2}$ [19]. The exercise test was considered maximal for a value of respiratory exchange ratio $($ RER $)>1.05$. All cardiopulmonary exercise tests were executed and interpreted by two expert operators.

All the tests were performed in the morning, after breakfast. T1DM patients did not modify their usual insulin dose, based on carbohydrate count or fasting glucose levels. 
Subjects were also asked to avoid the ingestion of alcohol caffeine-containing products and to refrain from strenuous activity for at least $12 \mathrm{~h}$ before testing. Glucose levels were measured before the test, at peak exercise and in case of symptoms of hypoglycemia. Exercise test was not performed if pre-test blood glucose was less than $5.56 \mathrm{mmol} / \mathrm{L}$ or greater than $13.9 \mathrm{mmol} / \mathrm{L} \mathrm{[23].}$

\section{Statistical analysis}

Considering the small sample size and the non-Gaussian distribution of the study population, non-parametric tests were applied. Results are expressed as median and range. Groups were compared using Kruskal-Wallis test. Bivariate correlation analysis was performed using Spearman coefficient. Statistical analysis was performed using the SPSS statistical software, version 22 (SPSS Inc.-Chicago, IL). Results were considered statistically significant for a $p$ value $<0.05$.

\section{Results}

Anthropometric and metabolic parameters of T1DM and healthy subjects are reported in Table 1 . There is a nonstatistically significant difference of age between the two groups; however, such a difference is attenuated by the use of the Hansen-Wasserman formula [24] to estimate the predicted values for $\mathrm{V}^{\prime} \mathrm{O}_{2}$,peak, which applies a value of 30 years for subjects younger than 30 years, thus reducing age difference in expected $\mathrm{V}^{\prime} \mathrm{O}_{2 \text {,peak }}$ values. CPET results are shown in Table 2. All subjects performed a maximal CPET (RER > 1.05). Diabetic subjects reached a maximum workload (W max) of $165 \pm 9.7 \mathrm{~W}$, while healthy subjects reached a maximum load of $198 \pm 6.9 \mathrm{~W}$. The difference was statistically significant $(p=0.007)$.

Mean oxygen uptake at peak exercise $\left(\mathrm{V}^{\prime} \mathrm{O}_{2, \text { peak }}\right)$ was significantly $(p=0.035)$ lower in T1DM subjects with absolute value of $2220 \pm 132 \mathrm{ml} / \mathrm{min}$ and a value of $28.1 \pm 1.3 \mathrm{ml} / \mathrm{min} / \mathrm{kg}$ when corrected by body weight $(79 \%$ of the predicted theoretical value). Healthy subjects had an oxygen uptake of $2659 \pm 120 \mathrm{ml} / \mathrm{min}$ and $35.5 \pm 1.1 \mathrm{ml} /$ $\mathrm{min} / \mathrm{kg}$ ( $87 \%$ of the predicted theoretical value). Considering a normal threshold of $80 \%$ of predicted value 11 diabetic patients $(64 \%)$ and 8 healthy volunteers $(47 \%)$ had reduced exercise tolerance (Table 2 ; Fig. 1). No ventilatory limitation was found in both groups (Table 2). Cardiovascular response analysis did not show statistically significant differences for heart rate (pre-test, at peak exercise and during recovery) and chronotropic response, expressed as heart rate to oxygen uptake ratio $\left(\mathrm{HR} / \mathrm{VO}_{2}\right)$ (Table 2). No arrhythmic or ischaemic events were observed. Anaerobic threshold was reached at $45 \pm 1.5 \%$ of predicted theoretical $\mathrm{V}^{\prime} \mathrm{O}_{2 \text {,peak }}$ by $\mathrm{T} 1 \mathrm{DM}$ subjects and at $47 \pm 2.8 \%$ by healthy subjects. Pre-test RER values were similar in the two groups, but significantly higher in healthy subjects at peak exercise and at the first recovery minute $(p=0.022$, $p=0.024$ ) (Fig. 2).

\section{Laboratory tests}

There was no difference in the pre-test lactate levels, though peak exercise lactate levels were significantly higher in healthy subjects $(p=0.027)$. Blood glucose levels were significantly higher in T1DM group $(p=0.000)$, as expected, and remained stable throughout the whole duration of the test. No hypoglycemic events were reported (Table 3 ).
Table 1 Anthropometric and metabolic parameters

\begin{tabular}{llll}
\hline & Non-T1DM (17) & T1DM (17) & $p$ \\
\hline Age (years) & $27( \pm 1.2)$ & $34( \pm 1.8)$ & $\mathrm{ns}$ \\
Sex (M/F) & $13 / 4$ & $13 / 4$ & $\mathrm{~ns}$ \\
BMI $\left(\mathrm{Kg} / \mathrm{m}^{2}\right)$ & $23.6( \pm 0.4)$ & $23.5( \pm 0.7)$ & $\mathrm{ns}$ \\
Smokers & 9 & 6 & 0.03 \\
IPAQ (moderate/high) & $11 / 6$ & $10 / 7$ & $\mathrm{~ns}$ \\
Pre-test glucose (mmol/l) & $5.17( \pm 0.18)$ & $10.67( \pm 1.123)$ & $<0.001$ \\
HbA1c (mmol/l) & & $57( \pm 2.4)$ & \\
Diabetes duration (years) & & $10( \pm 1.1)$ & \\
Insulin (UI/Kg) & & $0.4( \pm 0.03)$ & \\
Time from insulin administration (min) & & $140( \pm 9)$ & \\
Insulin type (rapid-acting/human regular) & & $14 / 3$ & \\
Retinopathy & & $3 \mathrm{NPDR}$ & \\
Albuminuria & & 1 & \\
\hline
\end{tabular}

Study groups had similar anthropometric characteristics

$I P A Q$ International Physical Activity Questionnaire, NPDR non-proliferative diabetic retinopathy 
Table 2 Metabolic, ventilatory, and cardiovascular response
$V^{\prime} O_{2}$ oxygen uptake, $V^{\prime} O_{2}$,peak oxygen uptake at peak exercise, $V^{\prime} O_{2} L T$ oxygen uptake at lactate threshold, $V E$ minute ventilation, $H R$ heart rate, $S B P$ systolic blood pressure, $D B P$ diastolic blood pressure

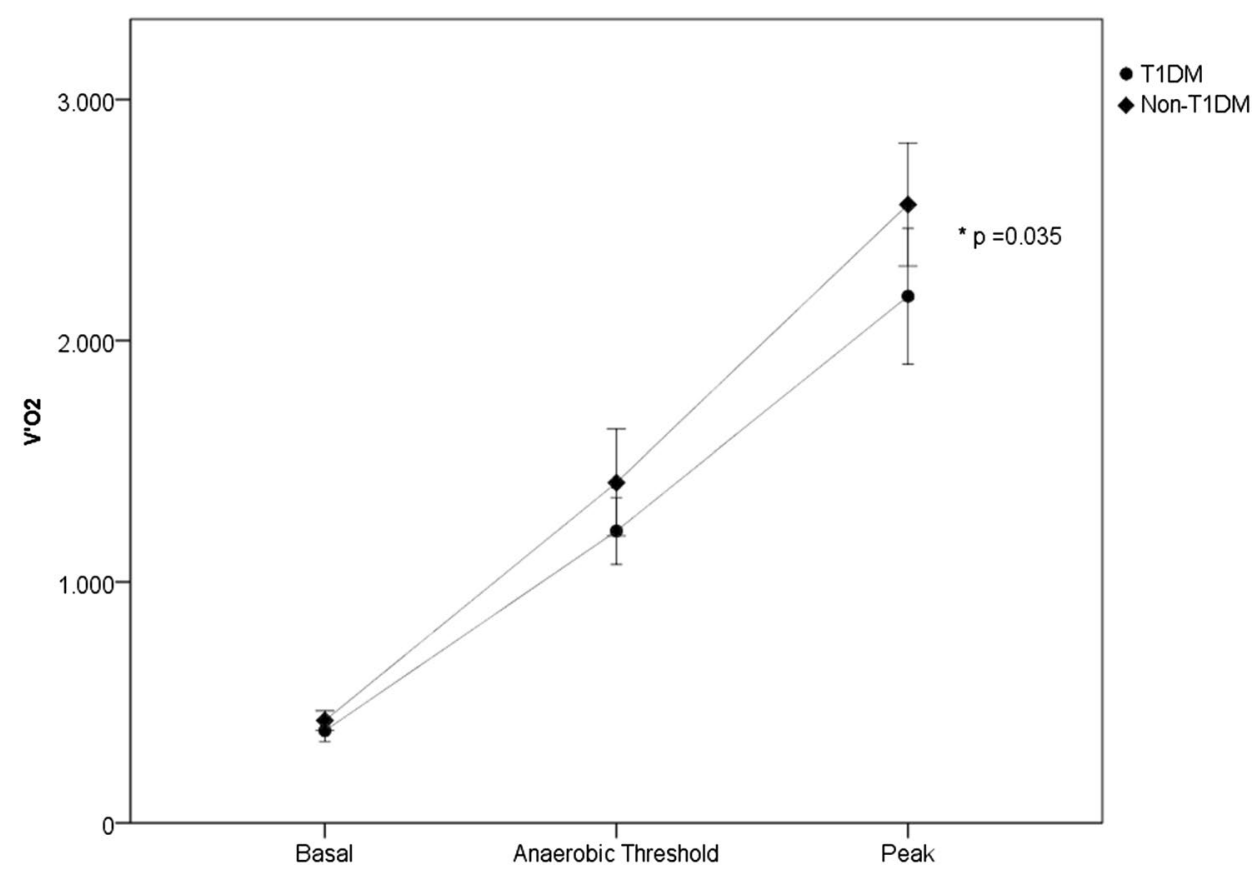

\begin{tabular}{llll}
\hline & Non-T1DM $(17)$ & $\mathrm{T} 1 \mathrm{DM}(17)$ & $p$ \\
\hline Watt max $(\mathrm{W})$ & $198( \pm 6.9)$ & $165( \pm 9.7)$ & $<0.007$ \\
$\mathrm{~V}^{\prime} \mathrm{O}_{2, \text { peak }}(\mathrm{ml} / \mathrm{min})$ & $2659( \pm 120)$ & $2220( \pm 132)$ & 0.035 \\
$\mathrm{~V}^{\prime} \mathrm{O}_{2, \text { peak }} / \mathrm{Kg}(\mathrm{ml} / \mathrm{min} / \mathrm{Kg})$ & $35.5( \pm 1.1)$ & $28.1( \pm 1.3)$ & 0.017 \\
$\mathrm{~V}^{\prime} \mathrm{O}_{2, \text { peak }}(\%$ predicted $)$ & $87( \pm 2.5)$ & $79( \pm 2.8)$ & 0.022 \\
$\mathrm{~V}^{\prime} \mathrm{O}_{2 \mathrm{LT}} / \mathrm{VO}_{2 \max }(\%$ predicted$)$ & $47( \pm 2.8)$ & $45( \pm 1.5)$ & $\mathrm{ns}$ \\
$\mathrm{V}^{\prime} \mathrm{O}_{2} / \mathrm{W}$ slope & $10.5( \pm 0.4)$ & $10.1( \pm 0.2)$ & $\mathrm{ns}$ \\
$\mathrm{Borg}$ rest/peak & $0 / 4( \pm 0.7)$ & $0 / 5( \pm 0-5)$ & $\mathrm{ns}$ \\
Leg rest/peak & $0 / 7( \pm 0.5)$ & $0 / 5( \pm 0.5)$ & $\mathrm{ns}$ \\
$\mathrm{Breathing} \mathrm{reserve}(\%)$ & $56( \pm 2.9)$ & $58( \pm 2.9)$ & $\mathrm{ns}$ \\
SpO & $98( \pm 0.1) / 98( \pm 0.2)$ & $\mathrm{ns}$ \\
$\mathrm{VE} / \mathrm{VCO}$ rest/peak $(\%)$ & $99( \pm 0.1) / 98( \pm 0.2)$ & $22.9( \pm 0.6)$ & $\mathrm{ns}$ \\
$\mathrm{HR}$ rest/peak $(\mathrm{bpm})$ & $22.4( \pm 0.6)$ & $87( \pm 4.4) / 162( \pm 4.1)$ & $\mathrm{ns}$ \\
$\mathrm{HR}$ peak $(\mathrm{bpm})$ & $80( \pm 2.3) / 170( \pm 2.9)$ & $162( \pm 4.1)$ & $\mathrm{ns}$ \\
$\mathrm{SBP} / \mathrm{DBP}$ rest $(\mathrm{mmHg})$ & $170( \pm 2.9)$ & $120( \pm 2.6) / 70( \pm 1.9)$ & $\mathrm{ns}$ \\
SBP/DBP peak $(\mathrm{mmHg})$ & $120( \pm 2.9) / 80( \pm 1.4)$ & $180( \pm 4.4) / 80( \pm 2.6)$ & $\mathrm{ns}$ \\
\hline
\end{tabular}

Fig. 1 Oxygen uptake $\left(\mathrm{V}^{\prime} \mathrm{O}_{2}\right)$ in basal condition, at anaerobic threshold and at peak exercise. The two groups had a similar oxygen uptake at baseline; $\mathrm{V}^{\prime} \mathrm{O}_{2}$ was higher in subjects without type 1 diabetes at anaerobic threshold, but the difference was not statistically significant. Oxygen uptake was significantly lower in type 1 diabetes patients at peak exercise $(p=0.035)$
There was no statistical correlation between CPET results and diabetes-related parameters (i.e., diabetes duration, HbA1c level, pre-test and peak exercise blood glucose, and insulin requirement).

\section{Discussion}

This preliminary study shows a statistically significant different exercise tolerance in diabetic subjects when expressed as $\mathrm{V}^{\prime} \mathrm{O}_{2 \text {,peak }}$, compared to a population of subjects matched for age, anthropometric parameters, and training level. The selection of young subjects, with relatively short duration of diabetes $(<15$ years), with acceptable metabolic control, reduced the possible confounding factors.

Cardiovascular diseases (CVD) are the most frequent cause of death in T1DM, with ten-fold increased CVD-related and all-cause mortality compared with the general population $[25,26]$. Diabetic patients develop 
Fig. 2 Respiratory exchange ratio during exercise and recovery. RER was lower in type 1 diabetic subjects during the whole exercise test and recovery. The differences were statistically significant at peak exercise and at the first minute of recovery. $R E R$ respiratory exchange ratio, $\operatorname{Rec} 1$ first minute of recovery, $\operatorname{Rec} 2$ second minute of recovery, Rec 4 fourth minute of recovery

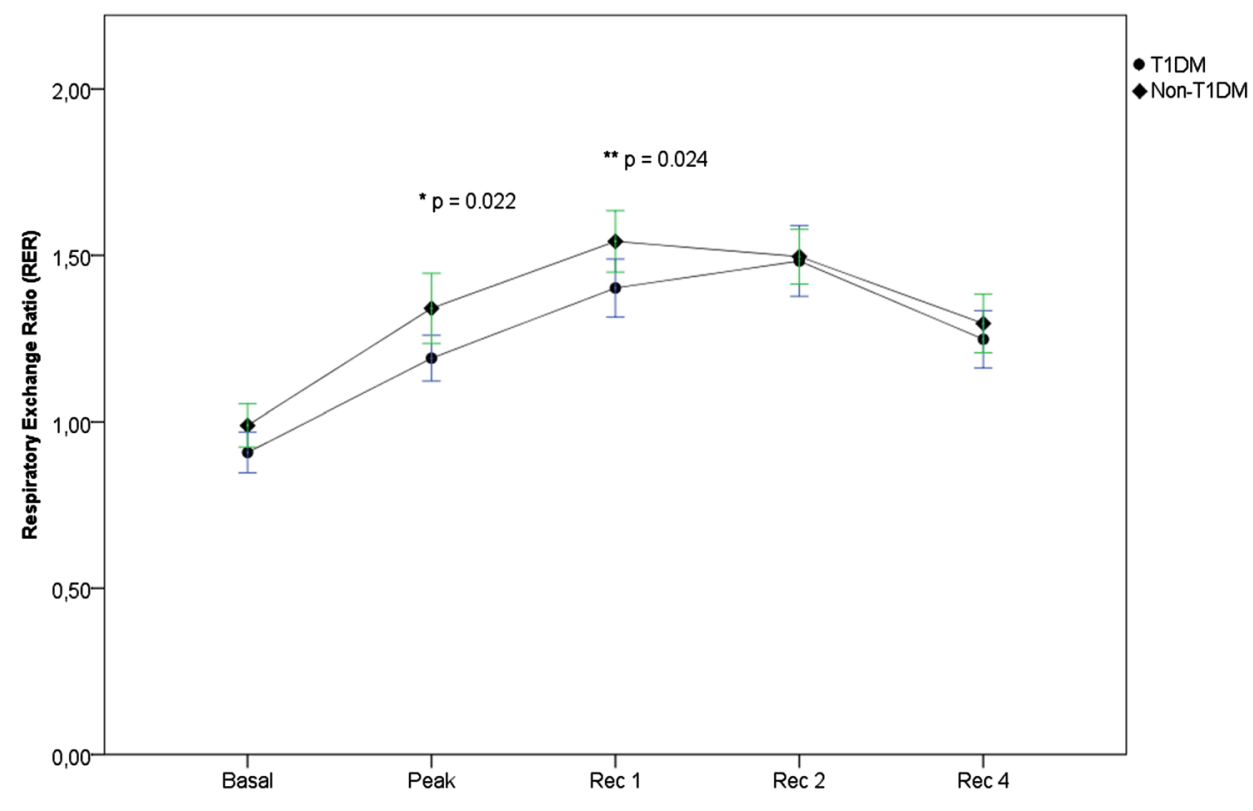

Table 3 Glucose and lactate levels

\begin{tabular}{llll}
\hline & Non-T1DM $(17)$ & T1DM $(17)$ & $p$ \\
\hline $\begin{array}{l}\text { Pre-test glucose (mmol/l) } \\
\text { Peak exercise glucose }\end{array}$ & $5.17( \pm 0.18)$ & $10.67( \pm 13)$ & 0.000 \\
$\quad$ (mmol/l) & $4.83( \pm 0.14)$ & $10.39( \pm 0.72)$ & 0.000 \\
$\begin{array}{l}\Delta \text { glucose (peak-pre) } \\
\quad(\mathrm{mmol} / \mathrm{l})\end{array}$ & $0( \pm 0.24)$ & $-0.06( \pm 0.43)$ & $\mathrm{ns}$ \\
$\begin{array}{l}\text { Pre-test lactate (mmol/l) } \\
\begin{array}{l}\text { Peak exercise lactate } \\
(\mathrm{mmol} / \mathrm{l})\end{array}\end{array}$ & $0.14( \pm 0.01)$ & $0.14( \pm 0.01)$ & $\mathrm{ns}$ \\
\hline
\end{tabular}

Glucose levels remained stable for all the duration of the test in both groups. Subjects with type 1 diabetes produced statistically significant lower levels of lactate, compared to normal subjects

atherosclerotic damage earlier than healthy subjects. Physical activity may play a pivotal role because of the possible action on multiple risk factors and positive effects on quality of life.

The pathophysiological mechanisms underlying metabolic and cardiovascular modifications in T1DM subjects have not been completely understood; furthermore, individual response to physical activity may be unpredictable.

The risk of hypoglycemic events frequently discourages physical activity in type 1 diabetic patients [26, 27] and up to $60 \%$ of diabetic patients do not perform a regular physical activity to avoid hypoglycemic events.

Our findings have excluded, in the present population, ventilatory limitations to physical exercise, as well as hemodynamic limitations and ischemic or arrhythmic events. The two groups differed by respiratory ratio (RER, the relationship between $\mathrm{CO}_{2}$ produced and $\mathrm{O}_{2}$ consumed) which can be greatly influenced by the substrate type utilized to produce energy [28, 29]. A lower RER is generally associated with prevalent lipid substrate utilization. Lower levels of lactate and pyruvate have been described in T1DM patients during exercise test [30]. Plasmatic levels of lactate and pyruvate depend on glycogenolysis, which relies on anaerobic glycolysis [31]. Persistently high plasmatic insulin levels may inhibit the glycolytic response in diabetic patients, interfering with the production of substrates in the tricarboxylic acid cycle, which is very important for early energy production during physical activity [11, 32].

Because of the impaired carbohydrate utilization, T1DM subjects may use a larger amount of lipid substrates, such hypothesis could be strengthened by the lower lactate levels found in T1DM group at peak exercise.

The lack of correlation between exercise tolerance and disease-related variables suggests that the alterations found could be independent from the glycemic levels and more probably linked to the complex underlying hormonal and metabolic alterations of T1DM. Stubbe et al. [14] did not find an association with $\mathrm{HbA1c}$ and exercise parameters as well.

There is a statistically significant difference in smoking habit between the two groups that could be a limit of the study. Anyhow, the most important limitations of the study come from small sample size and a male/female sex ratio favoring the former. A further limit of the study is represented by the use of IPAQ questionnaire to assess physical activity level, which is a self-reported questionnaire that may lack objectivity. Another possible confounding factor may be represented by the absence of a standardized meal for T1DM group, with a slightly different time interval between insulin administration and test execution; anyhow, 
a changing in the subject's usual meal could have produced unexpected glycemic variations and could have required insulin dose adjustments.

\section{Conclusions}

Patients affected by type 1 diabetes mellitus have a worse exercise tolerance than healthy subjects with similar anthropometric characteristics and training level. Such alteration seems to be linked to different metabolic substrate utilization. Further studies are, however, needed to fully understand the complex network of T1DM metabolic alterations.

Physical activity is a very important therapeutic intervention in chronic diseases because of its pleiotropic effects and CPET may help in the development of a personalized physical activity program through a better analysis of the individual response to exercise test, allowing improved compliance to physical activity.

\section{Compliance with ethical standards}

Conflict of interest The authors declare that they have no competing interests.

Ethical approval The study was conducted in compliance with ethical standards, research involving human subjects.

Informed consent Written informed consent was obtained from each subject. The study was approved by the Internal Review Board (IRB) and the local Ethics Committee.

\section{References}

1. American Diabetes Association (2014) Standards of medical care in diabetes-2014. Diabetes Care 37(Suppl 1):S14-S80

2. DCCT (1993) The effect of intensive treatment of diabetes on the development and progression of long-term complications in insulin-dependent diabetes mellitus, Diabetes Control and Complications Trial Research Group. N Engl J Med 329:977-986

3. Knowler WC, Barrett-Connor E, Fowler SE, Hamman RF, Lachin JM, Walker EA, Nathan DM, Diabetes Prevention Program Research Group (2002) Reduction in the incidence of type 2 diabetes with lifestyle intervention or metformin. N Engl J Med 346(6):393-403

4. Leon AS, Rice T, Mandel S, Després JP, Bergeron J, Gagnon J, Rao DC, Skinner JS, Wilmore JH, Bouchard C (2000) Blood lipid response to 20 weeks of supervised exercise in a large biracial population: the HERITAGE Family Study. Metabolism 49(4):513-520

5. Chimen M, Kennedy A, Nirantharakumar K, Pang TT, Andrews R, Narendran P (2012) What are the health benefits of physical activity in type 1 diabetes mellitus? Aliterature review. Diabetologia 55(3):542-551

6. Bohn B, Herbst A, Pfeifer M, Krakow D, Zimny S, Kopp F, Melmer A, Steinacker JM, Holl RW, DPV Initiative (2015) Impact of physical activity on glycemic control and prevalence of cardiovascular risk factors in adults with type 1 diabetes: a cross-sectional multicenter study of 18,028 patients. Diabetes Care 38(8):1536-1543

7. Baldi JC, Cassuto NA, Foxx-Lupo WT, Wheatley CM, Snyder EM (2010) Glycemic status affects cardiopulmonary exercise response in athletes with type I diabetes. Med Sci Sports Exerc 42:1454-1459

8. Benbassat CA, Stern E, Kramer M, Lebzelter J, Blum I, Fink G (2001) Pulmonary function in patients with diabetes mellitus. Am J Med Sci 322:127-132

9. Veves A, Saouaf R, Donaghue VM, Mullooly CA, Kistler JA, Giurini JM, Horton ES, Fielding RA (1997) Aerobic exercise capacity remains normal despite impaired endothelial function in the micro- and macrocirculation of physically active IDDM patients. Diabetes 46(11):1846-1852

10. Gusso S, Hofman P, Lalande S, Cutfield W, Robinson E, Baldi JC (2008) Impaired stroke volume and aerobic capacity in female adolescents with type 1 and type 2 diabetes mellitus. Diabetologia 51:1317-1320

11. Komatsu WR, Gabbay MA, Castro ML, Saraiva GL, Chacra AR, de Barros Neto TL, Dib SA (2005) Aerobic exercise capacity in normal adolescents and those with type 1 diabetes mellitus. Pediatr Diabetes 6:145-149

12. Niranjan V, McBrayer DG, Ramirez LC, Raskin P, Hsia CC (1997) Glycemic control and cardiopulmonary function in patients with insulin-dependent diabetes mellitus. Am J Med 103:504-513

13. Wanke T, Formanek D, Auinger M, Zwick H, Irsigler K (1992) Pulmonary gasexchange and oxygen uptake during exercise mellitus. Diabet Med 9:252-257

14. Stubbe B, Schipf S, Schäper C, Felix SB, Steveling A, Nauck M, Völzke H, Wallaschofski H, Friedrich N, Ewert R, Ittermann T, Gläser S (2017) The influence of type 1 diabetes mellitus on pulmonary function and exercise capacity-results from the Study of Health in Pomerania (SHIP). Exp Clin Endocrinol Diabetes 125(1):64-69

15. Zhang S, Zheng C, Lanza IR, Nair KS, Raftery D, Vitek O (2009) Interdependence of signal processing and analysis of urine $1 \mathrm{H} \mathrm{NMR}$ spectra for metabolic profiling. Anal Chem 81(15):6080-6088

16. Devlin JT, Scrimgeour A, Brodsky I, Fuller S (1994) Decreased protein catabolism after exercise in subjects with IDDM. Diabetologia 37(4):358-364

17. Lanza IR, Zhang S, Ward LE, Karakelides H, Raftery D, Nair KS (2010) Quantitative metabolomics by H-NMR and LC-MS/ MS confirms altered metabolic pathways in diabetes. PLoS One 5(5):e10538

18. Craig CL, Marshall AL, Sjöström M, Bauman AE, Booth ML, Ainsworth BE et al (2003) International physical activity questionnaire: 12-country reliability and validity. Med Sci Sports Exerc 35(8):1381-1395

19. American Thoracic Society; American College of Chest Physicians (2003) ATS/ACCP statement on cardiopulmonary exercise testing. Am J Respir Crit Care Med 167:211-277

20. Borg GA (1982) Psychophysical basis of perceived exertion. Med Sci Sports Exerc 14:377-381

21. Wasserman K, Hansen JE, Sue DY, Casaburi R, Whipp BJ (2005. Principles of exercise testing and interpretation. 4th edn. Lippincott, Williams \& Wilkins, pp. 144-145

22. Wasserman K (1984) The anaerobic threshold measurement to evaluate exercise performance. Am Rev Respir Dis, 129(Suppl):S35-40

23. Colberg SR, Sigal RJ, Fernhall B, Regensteiner JG, Blissmer BJ, Rubin RR, Chasan-Taber L, Albright AL, Braun B. American College of Sports Medicine; American Diabetes Association (2010) Exercise and type 2 diabetes: the American 
College of Sports Medicine and the American Diabetes Association: joint position statement. Diabetes Care 33:12

24. Bruce RA, Kusumi F, Hosmer D (1973) Maximal oxygen intake and nomographic assessment of functional aerobic impairment in cardiovascular disease. Am Heart J 85:546-562

25. Nadeau KJ, Reusch JEB (2011) “Cardiovascular function/dysfunction in adolescents with type 1 diabetes". Curr Diabetes Rep 11(3): 185-192

26. Laing S, Swerdlow A, Slater S et al (2003) Mortality from heart disease in a cohort of 23,000 patients with insulin-treated diabetes. Diabetologia 46:760-765

27. Brazeau AS, Rabasa-Lhoret R, Strychar I et al (2008) Barriers to physical activity among patients with type 1 diabetes. Diabetes Care 31(11):2108-2109

28. Zoppini G, Carlini M, Muggeo M (2003) Self-reported exercise and quality of life in young type 1 diabetic subjects. Diabetes NutrMetab 16:77-80

29. Frayn KN (1983) Calculation of substrate oxidation rates in vivo from gaseousexchange. J Appl Physiol Respir Environ Exerc Physiol 55(2):628-634
30. Brugnara L, Vinaixa M, Murillo S, Samino S, Rodriguez MA, Beltran A, Lerin C, Davison G, Correig X, Novials A (2012) Metabolomics approach for analyzing the effects of exercise in subjects with type 1 diabetes mellitus. PLoS One 7(7):e40600 (Epub 2012 Jul 11)

31. Lewis GD, Farrell L, Wood MJ, Martinovic M, Arany Z, Rowe GC, Souza A, Cheng S, McCabe EL, Yang E, Shi X, Deo R, Roth FP, Asnani A, Rhee EP, Systrom DM, Semigran MJ, Vasan RS, Carr SA, Wang TJ, Sabatine MS, Clish CB, Gerszten RE (2010) Metabolic signatures of exercise in human plasma. Sci Transl Med 2(33):33ra37

32. Bowtell JL, Marwood S, Bruce M, Constantin-Teodosiu D, Greenhaff PL (2007) Tricarboxylic acid cycle intermediate pool size: functional importance for oxidative metabolism in exercising human skeletal muscle. Sports Med 37(12):1071-1088 